\title{
THERMOLUMINESCENCE (TL) DATING OF ANCIENT SYRIAN POTTERY FROM SIX DIFFERENT ARCHAEOLOGICAL SITES
}

\author{
ELIAS H. BAKRAJI, NADA BOUTROS and RANA ABBOUD \\ Department of Chemistry, Atomic Energy Commission, P.O. Box 6091, Damascus, Syria
}

Received 6 July 2011

Accepted 23 October 2013

\begin{abstract}
Syrian archaeological pottery sherds were collected for TL dating from six different archaeological sites named Al-Shermanieh, Tell Serah, Der Al-Hajar (south of Damascus), Tell AlShekdakah, Tell Al-Souwirieh (east of Damascus) and Khurbet Al-Kulieh (south west of Damascus). The samples were prepared by fine grain technique and the annual dose for each sample (pottery sherds and soil sample) was measured using an alpha spectrometer system for uranium and thorium contribution as well as with atomic absorption spectrometry for the potassium contents. The mean ages were found to be $5500 \pm 150$ years, $2950 \pm 50$ years, $1200 \pm 50$ years, $1300 \pm 150$ years, $3300 \pm 100$ years and $3400 \pm 200$ years for the examined pottery from the sites Al-Shermanieh, Tell Serah, Der Al-Hajar, Tell Al-Shekdakah, Tell Al-Souwirieh and Khurbet Al-Kulieh, respectively. The results were in good agreement with the ages estimated by archaeologists except for one sample which belongs to Der Al-Hjar site.
\end{abstract}

Keywords: thermoluminescence, dating, ancient pottery, Syria.

\section{INTRODUCTION}

In respect with the considerable Syrian cultural heritage, special attention was recently given to the application of physics science in archaeology, such as X-ray fluorescence (XRF), particle induced x-ray emission (PIXE), thermoluminescence (TL). In this work we applied the TL technique to date a few pieces ceramics recently excavated from various Syrian archaeological sites.

Thermoluminescence (TL) and optically stimulated luminescence (OSL) techniques are the only presently available means of determining the absolute age of pottery. TL dating is nowadays a powerful technique which supports the archaeological and archaeometric research (Sanjurjo Sanchez et al., 2008; Hagihara et al., 1999; Abdel-Wahab et al., 1996; Martini and Sibilia 2006).

Corresponding author: E. H. Bakraji

e-mail: cscientific@aec.org.sy
Usually, clay samples contain a few parts per million of uranium and thorium and a few per cent of potassium, and therefore the mass of an ancient pot receives a natural radiation. Part of this energy is stored in the constituent insulating or semiconducting minerals of the clay either in the form of new lattice defects or as charge accumulated in the already existing impurity traps. During heating, some of this energy is emitted as light. In the majority of cases, we assume that, in pottery making, clay must have been fired at temperatures as high as about $800^{\circ} \mathrm{C}$ in antiquity, so that accumulation of stored energy begins anew from that time, and there is the possibility, first suggested by Daniels et al. (1953), that the thermoluminescent glow observed from ancient pottery could be used as a measure of its age. This technique has been most commonly applied for the dating of pottery, earthenware, bricks vessels, and hearths in archaeology (Fleming, 1979; Aitken, 1985). This technique makes use of the 
mineral grains, where quartz is the mineral usually used in TL dating. Luminescence dating is a measuring process of the light, resulting from the release of electrons and holes from metastable trapping states of crystal defects, in which a proportion of the ionizing radiation emitted by sources either external or internal to the mineral grain, has been stored (Mekeever, 1985; Martini and Meinardi 1997). By comparing this light output with that produced by known doses of radiation, the amount of radiation absorbed by the material can be estimated. Principles and mechanism of the TL is described elsewhere in literature (Aitken, 1985, Curie, 1963, Aitken, 1990). The age of the pottery is estimated by the equation:

$$
\text { Age }(\text { Year })=\frac{\text { Absorbed dose }(G y)}{\text { Annual dose rate }(G y / \text { year })}
$$

where absorbed dose, (also called the palaeodose), is the absorbed dose by the sample over its exposure to natural ionizing radiation, and the annual dose is the rate at which the palaeodose is being absorbed by the sample per year.

Most dating techniques were developed on the basis of differences in absorbing radiation by grains of different sizes. The so called "coarse grains" technique (Curie, 1963) considers only quartz grain of more than $90 \mathrm{mi}-$ crometer diameter extracted from the ceramics. The second major TL technique is the "fine grain" (Zimmerman, 1967 and 1971), which makes use of all the material that can be extracted. In the present work we used the second technique, where fine grain (taken as $1-8$ micrometre diameter grains with a mixed mineralogy, i.e., containing both quartz and feldspars) receive gamma radiation from the soil surrounding the piece of pottery, and both beta and alpha radiation from within the piece of pottery (Wintle, 2008).

The pottery sherds studied were extracted from six different archaeological sites around Damascus city, Syria, named Al-Shermanieh, Tell Serah, Der Al-Hajar, Tell Al-Shekdakah, Tell Al-Souwirieh and Khurbet Al-Kulieh, (see Fig. 1)

The aim of our study was to estimate the age of each site by taking the average date of three samples from each site, analyzed by thermoluminescence dating. The samples were labelled as follows: A-1, B-1 and C-1, from Al-Shermanieh site, A-2, B-2 and C-2 from Tell Serah site, A-3, B-3 and C-3, from Der Al-Hajar site, A-4, B-4 and C-4, from Tell Al-Shekdakah site, A-5, B-5 and C-5, from Tell Al-Souwirieh site, and finally A-6, B-6 and C-6, from Khurbet Al-Kulieh site. The dates assigned by archaeologists for pottery from each site are presented in Table 1 (last column).

\section{DESCRIPTION OF MATERIALS}

The excavations at these sites initiated since 2007 at the behest of Syrian Directorate of antiquities. All sites are around Damascus city, three of them (Al-Shermanieh, Tell Serah and Der Al-Hajar) are located south of Damascus, and two of them (Tel Al-Souwirieh and Tell Al-Shekdakah) are located east of Damascus and the final one (Khurbet Al-Kulieh) is located south west of Damascus.

\section{Pottery from sites south of Damascus}

Sherds from Al-Shermanieh are a base of large bowl, thick and poorly made, found in a tomb. For the first time archaeologists discover this kind of pottery around Damascus city. Archaeologists believed that the samples belong to the Stone-Copper Age. The archaeological sites dating to this era are very few around Damascus area.

The samples of Tell Serah are nozzle of vessel. From the appearance of the pottery they belong, according to archaeologists, to ages before Christ. Therefore it was necessary to be sure of the age of these pottery fragments. The samples of Der Al-Hajar site were pieces of vessel brown in colour tending to yellow. The archaeologists did not detect a similar type of this pottery earlier in Syria. The form of pottery did not help archaeologists to estimate their age. There was a doubt that the samples are belonging to the period $2000 \mathrm{BC}$. Since this new type of pottery was not known previously, their dating was crucial to be sure of their age.

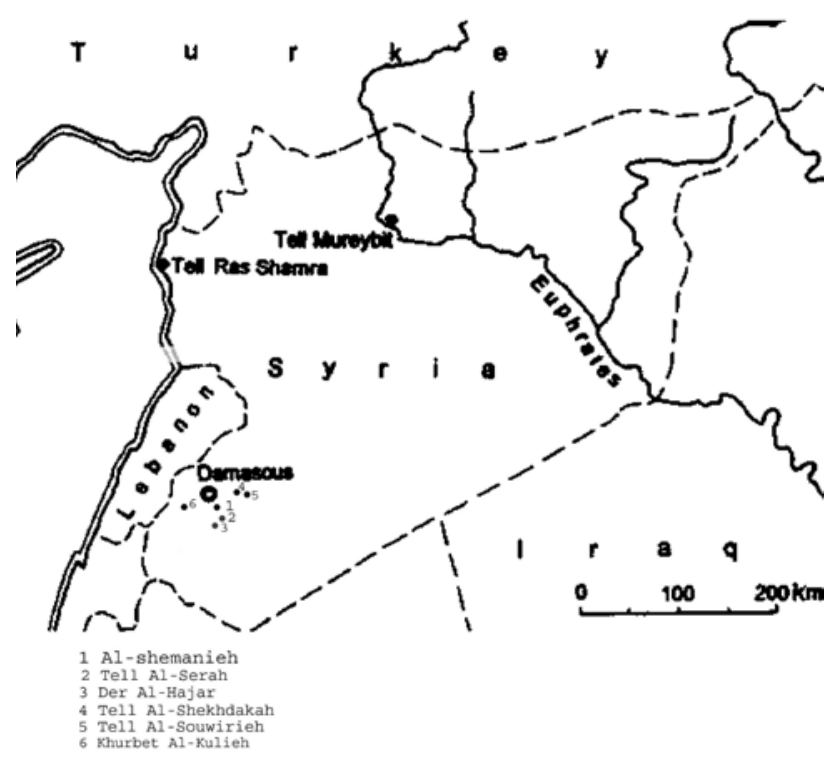

Fig. 1. Map of Syria with the six studied archaeological sites. 
Table 1. Annual dose, archaeodose (ED + supraliniarity correction), the ages calculated and the ages assigned by archaeologists for the pottery sherds investigated.

\begin{tabular}{|c|c|c|c|c|c|c|}
\hline Site & $\begin{array}{c}\text { Annual dose } \\
\text { (mGy/y) }\end{array}$ & Sample & $\begin{array}{c}\text { Archaeodose (ED + I) } \\
(\mathrm{Gy})\end{array}$ & $\begin{array}{c}\text { Age } \\
\text { (year BP) }\end{array}$ & $\begin{array}{l}\text { Mean age } \\
\text { (year BP) }\end{array}$ & $\begin{array}{l}\text { Date assigned by ar- } \\
\text { chaeologists (year BP) }\end{array}$ \\
\hline & & $A-1$ & $17.4 \pm 0.9$ & $5524 \pm 325$ & & \\
\hline \multirow[t]{3}{*}{ Al-Shermanieh } & $3.15 \pm 0.08$ & $B-1$ & $16.6 \pm 1.0$ & $5270 \pm 357$ & $5500 \pm 150$ & $4000-6000$ \\
\hline & & C-1 & $17.5 \pm 1.2$ & $5556 \pm 411$ & & \\
\hline & & A-2 & $8.6 \pm 0.7$ & $2925 \pm 252$ & & \\
\hline \multirow[t]{3}{*}{ Tell Serah } & $2.94 \pm 0.09$ & B-2 & $8.6 \pm 0.8$ & $2925 \pm 285$ & $2950 \pm 50$ & $2000-3000$ \\
\hline & & $\mathrm{C}-2$ & $8.8 \pm 0.8$ & $2993 \pm 284$ & & \\
\hline & & A-3 & $4.5 \pm 0.4$ & $1250 \pm 130$ & & \\
\hline \multirow[t]{3}{*}{ Der Al-Hajar } & $3.60 \pm 0.11$ & B-3 & $4.3 \pm 0.4$ & $1194 \pm 123$ & $1220 \pm 30$ & $3000-4000$ \\
\hline & & C-3 & $4.4 \pm 0.5$ & $1222 \pm 133$ & & \\
\hline & & A-4 & $3.0 \pm 0.3$ & $1111 \pm 118$ & & \\
\hline \multirow[t]{3}{*}{ Tell Al-Shekdakah } & $2.70 \pm 0.07$ & B-4 & $3.6 \pm 0.3$ & $1333 \pm 120$ & $1270 \pm 130$ & $1100-1500$ \\
\hline & & C-4 & $3.7 \pm 0.4$ & $1352 \pm 155$ & & \\
\hline & & $A-5$ & $12.3 \pm 1.2$ & $3455 \pm 353$ & & \\
\hline \multirow[t]{3}{*}{ Tell Al-Souwirieh } & $3.56 \pm 0.09$ & B-5 & $11.9 \pm 0.9$ & $3343 \pm 280$ & $3340 \pm 110$ & $3000-5000$ \\
\hline & & C-5 & $11.5 \pm 1.0$ & $3230 \pm 298$ & & \\
\hline & & $A-6$ & $10.2 \pm 0.9$ & $3228 \pm 306$ & & \\
\hline \multirow[t]{2}{*}{ Khurbet Al-Kulieh } & $3.16 \pm 0.09$ & B-6 & $10.8 \pm 0.9$ & $3418 \pm 267$ & $3418 \pm 190$ & $3000-5000$ \\
\hline & & C-6 & $11.4 \pm 0.8$ & $3608 \pm 280$ & & \\
\hline
\end{tabular}

\section{Pottery from sites east of Damascus}

Samples of Tell Al-Souwirieh are pieces of vessel with smooth surface, and there are no buildings visible above the site. The archaeologists noticed that the pottery were similar to the pottery of Tel Al-Baharia site (Bakraji, 2004). The expected age of the samples was between 3000 and $5000 \mathrm{BC}$. So the dating of the samples help archaeologists to make sure of their conclusion. The samples of Tell Al-Shekdakah site are part of the crater thick bowl, with beige colour. The archaeologists doubt that the samples belong to the early Islamic period.

\section{Pottery from site south west of Damascus}

Samples from Khurbet Al-Kulieh are part of brown vessel. The apparent shape of the buildings belongs to the Romanian or Byzantine period, while the form of pottery back to $\mathrm{BC}$ times, so the samples were analysed to be sure of their age.

\section{THEMOLUMINESCENCE MEASURING TECH- NIQUE}

\section{Sample collection}

The level (depth) from which the pottery were collected ranges between $0.3-0.5 \mathrm{~m}$ below the present surface. The analysis of the pottery by XRD showed that the percentage of feldspar in the samples was too small, therefore the anomalous fading can be passed over. In addition to the pottery sherds an adequate amount of soil surrounding the buried pottery was taken from each site to determine the dose rate which the pottery has been exposed to.

\section{Sample preparation}

The preparation procedure was carried out in subdued red light to avoid bleaching effects. To eliminate the beta dose contribution from the soil, we removed about $3 \mathrm{~mm}$ of the pottery's outer surface. Then drilled the sample until we obtained an adequate quantity of powder (about $250 \mathrm{mg}$ ). Calcite grain are removed with hydrochloric acid $(10 \% \mathrm{HCl})$ and organic material was removed by using oxygen peroxide $\left(10 \% \mathrm{H}_{2} \mathrm{O}_{2}\right)$. We wash the product in acetone and then wait for $2 \mathrm{~min}$. for a $60 \mathrm{~mm}$ column. We take the suspension and wait for $20 \mathrm{~min}$ for also $60 \mathrm{~mm}$ column to obtain the grain size range of $1-8 \mu \mathrm{m}$ for the fine-grain technique. The separated grains are then allowed to deposit on aluminium discs placed at the bottom of individual flat-bottomed glass tubes. The grains form a thin layer of a few $\mu \mathrm{m}$ thickness. Then we put them in an oven to evaporate the acetone. The discs are then placed, in the RISØ set, on the heater plate using tweezers (Aitken, 1985).

\section{Measurements}

The TL measurements were performed using an automated RIS $\varnothing$ TL/OSL reader model DA-20, equipped with calibrated beta $\left({ }^{90} \mathrm{Sr} /{ }^{90} \mathrm{Y}\right)$ and alpha $\left({ }^{241} \mathrm{Am}\right)$ sources with a dose rate of $0.135 \mathrm{~Gy} / \mathrm{s}$ and $0.045 \mathrm{~Gy} / \mathrm{s}$ respectively, a photomultiplier tube (PMT), model 9235/0158/1498AMP, made in USA. The samples were placed on a controlled heated tray, and were heated to $500^{\circ} \mathrm{C}$ in $\mathrm{N}_{2}$ with temperature rising at rate of $5^{\circ} \mathrm{C} / \mathrm{s}$.

The first step in the analysis is to determine the region of thermal stability so each disk was measured twice in the same conditions, the second one is attributed to the 
background which was subtracted from the first measurement to obtain real TL glow curve. After the measurement of natural TL, artificial irradiation dose was applied and subsequent TL was measured to build up the plateau test in order to check the TL suitability of the samples by plotting the temperature against the ratio between TL natural signal and TL artificial signal. Our samples show a very good constant plateau test between $250-400^{\circ} \mathrm{C}$ and depending on this region we can determine the integrated temperature range, which we define to obtain the plot of additive dose later.

\section{RESULTS AND DISCUSSION}

\section{Accumulated dose (Palaeoadose)}

To estimate the equivalent beta dose we used the multi aliquot additive dose (MAAD) procedure. A growth curve was constructed on the basis of four additive beta doses using three disks for each dose, assuming that the sensitivity to the laboratory radiation was the same as it has been for radiation during burial (Zimmerman, 1967).

Fig. 2 represents the TL glow curve of one sample (A-4) from Tell Al-Shekdakah site. Based on the plateau test the $\mathrm{ED}$ was measured by integration the TL curves between $290^{\circ} \mathrm{C}$ and $330^{\circ} \mathrm{C}$, Fig. 3 represents the growth curve for the same sample above. As it is known the intercept with the dose $=0$ axis (X-axis) gives the absorbed dose. Before using the obtained ED on Eq. 1.1 it must have been corrected for the supralinearity $(I)$, where the new palaeodose value $(P)$ is $P=E D+I$. The supralinearity correction was determined using the same disks which were used for measuring natural TL, a regeneration growth curve was constructed using TL signals measured after the irradiation with four small different known doses (see Fig. 3 as an example). We noticed from this figure that the supraliniarity correction for the sample A-4 is
0.6 Gy. The final archaeological dose for the samples analyzed, after taking into account the supraliniarity correction, are presented in Table 1.

\section{Annual dose (dose-rate)}

Alpha rays have the shortest range in geological materials (approximately $0.03 \mathrm{~mm}$ ), beta rays traverse up to $3 \mathrm{~mm}$ in solid matter, while gamma rays penetrate about $30 \mathrm{~cm}$, much greater than the dimensions of our pottery samples.

The assessment of the dose-rate to the sample from gamma and cosmic sources is referred to as the environmental dosimetry.

Before TL measurements are carried out upon our sherds, the outer $3 \mathrm{~mm}$ of the sample are cut away. The remaining portion has therefore received its alpha and

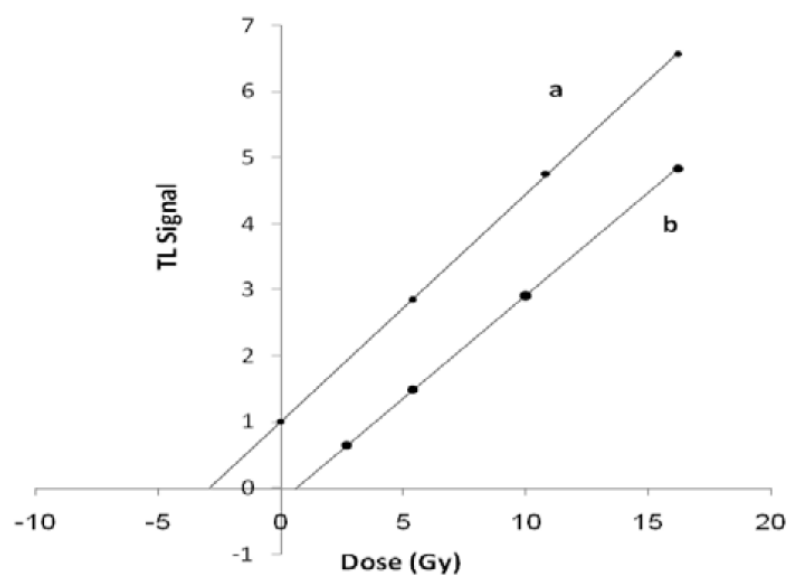

Fig. 3. Growth curve for sample (C-4) from Tell Al-Shekdakah (normalized signal): a) additive beta dose; b) second glow (for supralinearity correction).
Fig. 2. The TL glow curves, of Tell AlShekdakah sample, by fixed additive dose procedure. $N$ is the TL due to natural dose, $N+\beta$ is $T L$ due to natural and artificial dose. Temperature unit is ${ }^{\circ} \mathrm{C}$ and the intensity unit is counts/s.

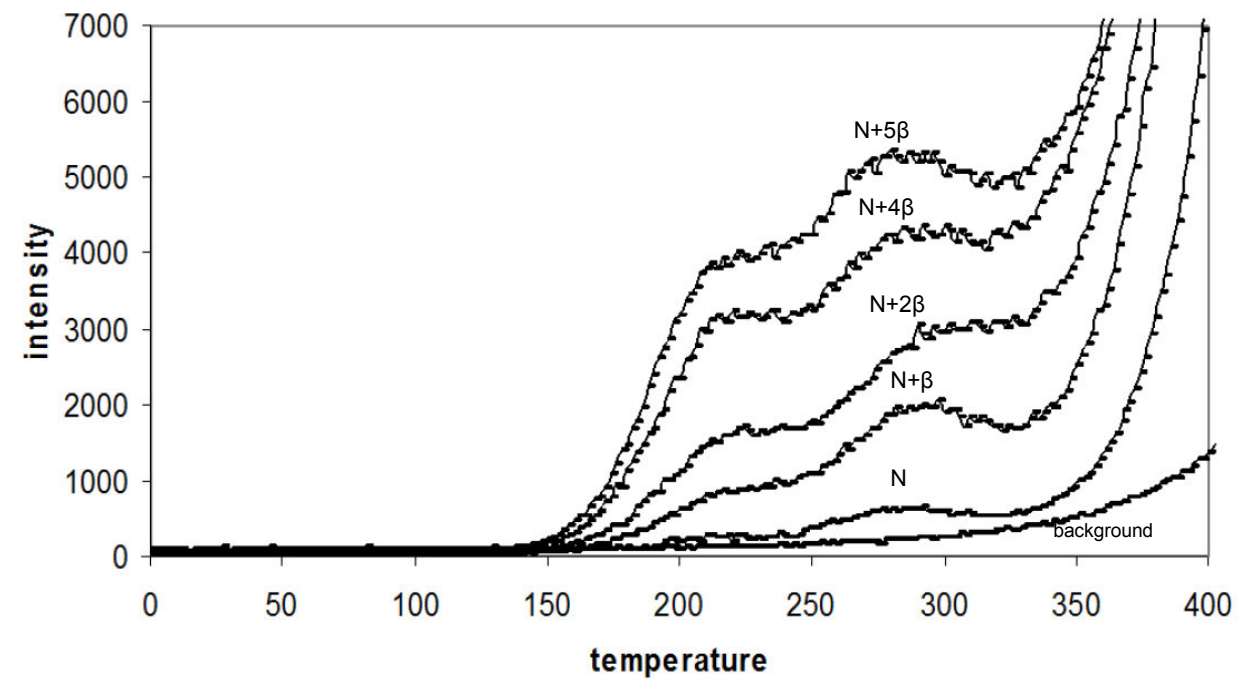


Table 2. Dose rate with type of radiation.

\begin{tabular}{|c|c|c|c|c|c|c|}
\hline \multirow{2}{*}{$\begin{array}{l}\text { Radiation I } \\
\text { Samples }\end{array}$} & \multicolumn{6}{|c|}{ Dose rate (Gy/ka) } \\
\hline & Al-Sherhmanieh & Tell Al-Sirah & Der Al-Hjar & Tell Al-Shekh dakah & Tell Al-Souwirieh & Khurbet alkulieh \\
\hline a-value & $a=0.12$ & $a=0.09$ & $a=0.16$ & $a=0.11$ & $a=0.14$ & $a=0.11$ \\
\hline$a$ (corrected) & $1.096 \pm 0.06$ & $0.852 \pm 0.06$ & $1.6 \pm 0.1$ & $0.9 \pm 0.06$ & $1.41 \pm 0.07$ & $1.2 \pm 0.06$ \\
\hline$\beta$ from $U$ & 0.198 & 0.212 & 0.188 & 0.18 & 0.198 & 0.218 \\
\hline$\beta$ from Th & 0.320 & 0.321 & 0.299 & 0.254 & 0.328 & 0.229 \\
\hline$\beta$ from $K$ & 0.582 & 0.601 & 0.512 & 0.443 & 0.611 & 0.543 \\
\hline Total $\beta$ & $1.10 \pm 0.05$ & $1.13 \pm 0.06$ & $1.00 \pm 0.05$ & $0.90 \pm 0.04$ & $1.14 \pm 0.05$ & $0.99 \pm 0.05$ \\
\hline$Y$ from U & 0.171 & 0.156 & 0.155 & 0.142 & 0.172 & 0.158 \\
\hline $\mathrm{y}$ from Th & 0.449 & 0.499 & 0.533 & 0.457 & 0.524 & 0.51 \\
\hline$Y$ from $K$ & 0.174 & 0.154 & 0.163 & 0.145 & 0.161 & 0.158 \\
\hline Total y & $0.80 \pm 0.03$ & $0.81 \pm 0.02$ & $0.85 \pm 0.02$ & $0.74 \pm 0.02$ & $0.86 \pm 0.03$ & $0.82 \pm 0.04$ \\
\hline Cosmic ray & 0.15 & 0.15 & 0.15 & 0.15 & 0.15 & 0.15 \\
\hline Total & $3.15 \pm 0.08$ & $2.94 \pm 0.09$ & $3.60 \pm 0.11$ & $2.70 \pm 0.07$ & $3.56 \pm 0.09$ & $3.16 \pm 0.09$ \\
\hline
\end{tabular}

beta dose entirely from within the volume of the sherd. This dose, termed the internal dose, can be determined from an examination of the sample alone.

Like the alpha and beta rays, gamma radiation derives from the decay of naturally occurring radionuclides present in the ground, such as potassium- 40 and members of the uranium and thorium decay series.

$\mathrm{U}$ and Th contents of samples and soils were determined by an alpha spectrometry system (Oasis, Oxford) with a passive ion-implanted silicon detector (active area $300 \mathrm{~mm}^{2}$, background 3.6 counts per day and the minimum depletion thickness of $100 \mu \mathrm{m})$. The lower limit of detection of the method used was $0.4 \mathrm{~Bq} \mathrm{~kg}^{-1}$ of dry weight. The radioactive element $\mathrm{K}$ of samples and soils was determined by atomic absorption spectrometry. The dose rates are presented in Table 2, where the internal contribution was calculated from alpha and beta activity measurements coming from the samples taking into account the alpha correction factor. To estimate the alpha attenuation factor (a-value) for each site we applied additive alpha dose technique (the procedures are the same as additive beta dose) using an ${ }^{241} \mathrm{Am}$ alpha source for new disks. By taking the ratio (beta ED/alpha ED) we estimated the a-value (Aitken, 1985). The a-values for each site are presented in Table 2. The external contribution was calculated from gamma activity coming from the soil. The dose rate conversion factor of alpha, beta and gamma has been done according to Aitken (1985) and the cosmic dose rate was assumed to be $0.15 \mathrm{~Gy} / \mathrm{ka}$ according to (Aitken, 1985) as the level (depth) from which the pottery were collected was less than one meter below the present earth surface. Finally the calculated age before present (BP), by applying Eq. 1.1, of the sherds from each site are presented in Table 1. The errors for the age determination, were calculated using the error propagation rules. The sixth column presents the mean age for each site with standard deviation (SD).

It is clear by comparing the age of sherds in Table 1 measured by using TL with the age of sherds estimated by archaeologists, that the results are in good agreement with the archaeological evidence, except for samples from Der Al-Hajar site, which need more investigation to be sure of its date.

\section{CONCLUSION}

Thermoluminescence technique was applied to dating Syrian archaeological pottery sherds from six different archaeological sites around Damascus city. The present work was the first application of thermoluminescence for TL dating, of the ancient pottery in Syria. It is clear by comparing the age of sherds in Table 1 measured by using TL with the age of sherds estimated by archaeologists, that the ages of the extracted pottery sherds were consistent with that estimated by archaeologists, except for one sample which belongs to Der Al-Hajar site, and the obtained ages show that the uncertainties in dating using TL technique are much lower than the age range estimated by archaeologists, for example, the mean age estimated by TL for Al-Shermanieh site is $5500 \pm 150$ years, while the mean age estimated by archaeologist for the same site is $5000 \pm 1000$ years. Then, the obtained results using thermoluminescence technique for dating of ancient Syrian pottery proved to be very valuable to the archaeologists. For Tell Serah site, for example, the form of constructions at the site dating from the Byzantine and Islamic period, while the form of pottery belongs to ages before Christ, therefore it was necessary to be sure of the age of the site, and the results obtained by TL dating confirmed that, the age of the site belongs to the Islamic period. From this result we can conclude that, it is not always accurate to estimate the age of a site according to the form of pottery.

The extension of the programme to other sites will be of significant value.

\section{ACKNOWLEDGEMENT}

The authors wish to thank the International Atomic Energy Agency (ARASIA 1/011/ project) and Prof. I. 
Othman General Director of AEC of Syria for supplying this work, and Dr. M. Hammoud from Syrian directorate of antiquity in Damascus for supplying the samples discussed in this study.

\section{REFERENCES}

Abdel-Wahab MS, El-Fiki SA, El-Foci MA, Gomaa M, Abdel-Kariem S, El-Faramawy N, 1996. Annual dose measurements and TLdating of ancient Egyptian pottery. Radiation Physics and Chemistry 47(5): 697-700, DOI 10.1016/0969-806X(95)00044-X.

Aitken MJ, 1985. Thermoluminescence Dating. Academic Press, New York, $359 \mathrm{pp}$.

Aitken MJ, 1990. Science-based dating in archaeology. Longman, London, $274 \mathrm{pp}$.

Bakraji EH, 2004. Analysis of Ancient Pottery from Tel Al-Baharia Site in Damascus, Syria. Instrumentation Science \& Technology 32(3): 263-270, DOI 10.1081/CI-120030538.

Curie D, 1963. Luminescence in Crystals. John Wiley \& Sons, Inc., New York, 332pp.

Daniels F, Boyd CA, Saunders DF, 1953. Thermoluminescence as a Research Tool. Science 117: 343-349, DOI 10.1126/science.117.3040.343.

Fleming SJ, 1979. Thermoluminescence Techniques in Archaeology.
Oxford, Clarendon Press: 30-33.

Hagihara N, Miono S, Chengzhi Z, Nakayama Y, Hanamoto K, 1999. The combined application of PIXE analysis and Thermoluminescence (TL) dating for elucidating the origin of iron manufacturing in Japan. Nuclear Instruments and Methods in Physics Research Section B: Beam Interactions with Materials and Atoms 150(1-4): 635-639, DOI 10.1016/S0168-583X(98)01077-5.

Martini M and Meinardi F, 1997. Thermally stimulated luminescence: new perspectives in the studyof defects in solid. La Rivista del Nuovo Cimento 20: 1-71.

Martini M and Sibilia E, 2006. Luminescence dating and cultural heritage. Archeometriai Muhely 1: 3-11.

Mekeever SWS, 1985. Thermoluminescence of solids. Cambridge University Press, Cambridge, 390 pp

Sanjurjo Sanchez J, Fernadez Mosquera D and Montero Fenollos JL, 2008. TL and OSL dating of sediment and pottery from two Syrian archaeological sites. Geochronometria 31: 21-29, DOI 10.2478/v10003-008-0017-6.

Wintle AG, 2008. Fifty years of luminescence dating. Archaeometry 50(2): 276-312, DOI 10.1111/j.1475-4754.2008.00392.x.

Zimmerman DW, 1967. Thermoluminescence from fine grains from ancient pottery Archaeometry 10(1): 26-8, DOI 10.1111/j.14754754.1967.tb00610.x.

Zimmerman DW, 1971. Thermoluminescence dating using fine grains from pottery. Archaeometry 13(1): 29-52, DOI 10.1111/j.14754754.1971.tb00028.x. 